\title{
GUIDE TO LINEAR ALGEBRA
}


Consultant Editor: David A. Towers,

Senior Lecturer in Mathematics, University

of Lancaster

Titles Available:
Abstract Algebra
Linear Algebra
Analysis

Further titles are in preparation. 


\section{Guide to Linear Algebra}

\section{David A. Towers}

Senior Lecturer in Mathematics

University of Lancaster

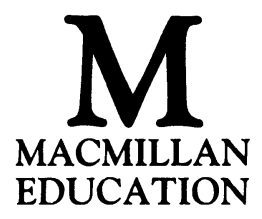


All rights reserved. No reproduction, copy or transmission of this publication may be made without written permission.

No paragraph of this publication may be reproduced, copied or transmitted save with written permission or in accordance with the provisions of the Copyright Act 1956 (as amended), or under the terms of any licence permitting limited copying issued by the Copyright Licensing Agency, 33-4 Alfred Place, London WC1E 7DP.

Any person who does any unauthorised act in relation to this publication may be liable to criminal prosecution and civil claims for damages.

First published 1988

Published by

MACMILLAN EDUCATION LTD

Houndmills, Basingstoke, Hampshire RG21 2XS

and London

Companies and representatives

throughout the world

British Library Cataloguing in Publication Data

Towers, David

Guide to linear algebra.-(Macmillan

mathematical guides).

1. Algebras, Linear

I. Title

$512^{\prime} .5$

QA184

ISBN 978-0-333-43627-1

DOI 10.1007/978-1-349-09318-2 


\section{CONTENTS}

Editor's foreword

viii

Preface

ix

1 VECTORS

1.1 Free vectors and position vectors 1

$\begin{array}{ll}1.2 & \text { Bases and coordinates }\end{array}$

$\begin{array}{llr}1.3 & \text { Scalar product } & 9\end{array}$

$\begin{array}{llr}1.4 & \text { Vector product } & 12\end{array}$

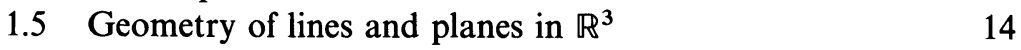

$\begin{array}{ll}\text { Solutions and hints for exercises } & 22\end{array}$

2 MATRICES $\quad 28$

$\begin{array}{lll}2.1 & \text { Introduction } & 28\end{array}$

2.2 Addition and scalar multiplication of matrices 30

$\begin{array}{lll}2.3 & \text { Matrix multiplication } & 33\end{array}$

$\begin{array}{lll}2.4 & \text { Properties of matrix multiplication } & 37\end{array}$

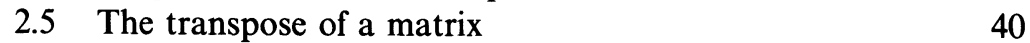

2.6 Invertible matrices $\quad 42$

Solutions and hints for exercises $\quad 45$

3 ROW REDUCTION $\quad 52$

3.1 Systems of linear equations $\quad 52$

3.2 Equivalent systems $\quad 56$

$\begin{array}{lll}3.3 & \text { Elementary row operations on matrices } & 60\end{array}$

3.4 The reduced echelon form for a matrix 61

$\begin{array}{lll}3.5 & \text { Elementary matrices } & 65\end{array}$

3.6 Finding the inverse of an invertible matrix 68

$\begin{array}{ll}\text { Solutions and hints for exercises } & 70\end{array}$ 
4 DETERMINANTS

4.1 The sign of a permutation $\quad 74$

4.2 The definition of a determinant $\quad 76$

$\begin{array}{lll}4.3 & \text { Elementary properties of determinants } & 79\end{array}$

$\begin{array}{lll}4.4 & \text { Non-singular matrices } & 85\end{array}$

$\begin{array}{lll}4.5 & \text { Cofactors } & 87\end{array}$

$\begin{array}{lll}\text { 4.6 The adjugate of a matrix } & 92\end{array}$

4.7 Systems of homogeneous linear equations 94

Solutions and hints for exercises $\quad 96$

5 VECTOR SPACES $\quad 102$

$\begin{array}{lll}5.1 \text { Introduction } & 102\end{array}$

5.2 Subspaces and spanning sequences 106

5.3 Linear independence and bases 109

5.4 The dimension of a vector space 112

$\begin{array}{ll}\text { Solutions and hints for exercises } & 117\end{array}$

6 LINEAR TRANSFORMATIONS

6.1 Introduction 124

$\begin{array}{ll}\text { 6.2 Invertible linear transformations } & 127\end{array}$

6.3 The matrix of a linear transformation 130

6.4 Kernel and image of a linear transformation 135

$\begin{array}{ll}\text { 6.5 The rank of a matrix } & 141\end{array}$

6.6 Systems of linear equations 146

Solutions and hints for exercises 151

7 EIGENVECTORS 160

$\begin{array}{lll}7.1 & \text { Changing the domain basis } & 160\end{array}$

$\begin{array}{ll}7.2 & \text { Changing the codomain basis } \\ 7.3\end{array}$

7.3 Changing the basis in both domain and codomain 165

$\begin{array}{lll}7.4 & \text { Eigenvalues and eigenvectors } & 166\end{array}$

7.5 The characteristic equation of a square matrix 169

Solutions and hints for exercises 172

8 ORTHOGONAL REDUCTION OF SYMMETRIC MATRICES

8.1 Orthogonal vectors and matrices 177

8.2 Euclidean transformations 180

8.3 Orthogonal reduction of a real symmetric matrix 184

8.4 Classification of conics 192 
8.5 Classification of quadrics

195

Solutions and hints for exercises

201

Index of notation

207

General index

208 


\section{EDITOR'S FOREWORD}

Wide concern has been expressed in tertiary education about the difficulties experienced by students during their first year of an undergraduate course containing a substantial component of mathematics. These difficulties have a number of underlying causes, including the change of emphasis from an algorithmic approach at school to a more rigorous and abstract approach in undergraduate studies, the greater expectation of independent study, and the increased pace at which material is presented. The books in this series are intended to be sensitive to these problems.

Each book is a carefully selected, short, introductory text on a key area of the first-year syllabus; the areas are complementary and largely selfcontained. Throughout, the pace of development is gentle, sympathetic and carefully motivated. Clear and detailed explanations are provided, and important concepts and results are stressed.

As mathematics is a practical subject which is best learned by doing it, rather than watching or reading about someone else doing it, a particular effort has been made to include a plentiful supply of worked examples, together with appropriate exercises, ranging in difficulty from the straightforward to the challenging.

When one goes fellwalking, the most breathtaking views require some expenditure of effort in order to gain access to them: nevertheless, the peak is more likely to be reached if a gentle and interesting route is chosen. The mathematical peaks attainable in these books are every bit as exhilarating, the paths are as gentle as we could find, and the interest and expectation are maintained throughout to prevent the spirits from flagging on the journey. 


\section{PREFACE}

'What! Not another linear algebra book!', I hear the reader cry-and with some justification. It is undoubtedly true that there is a very wide selection of books available on this topic, largely because it is so widely taught and applied, and because of the intrinsic beauty of the subject. However, while many of these books are very suitable for higher-level courses, fewer have been written with the specific needs of first-year undergraduates in mind. This guide is intended to be sympathetic to the problems often encountered during the transition from school to university mathematics, and this has influenced both the choice of material and its presentation.

All new concepts are introduced gently and are fully illustrated by examples. An unusual feature is the inclusion of exercises at the end of each section. A mathematical concept can be properly understood only by using it, and so it is important to develop and to test your understanding by attempting exercises after each new idea or set of ideas has been introduced. Many of these exercises are routine and are designed simply to help you to digest the definitions and to gain confidence. Others are more demanding and you should not be discouraged if you are unable to do them: sometimes a 'trick' ('insight' and 'inspiration' are commonly used synonyms) is involved, and most of us are inspired only very rarely. Nevertheless, much can be gained from wrestling with a difficult problem, even if a complete solution is not obtained. Full solutions to almost all of the exercises are included at the end of each chapter in order to make the book more useful if you are studying alone (and, I hope, to allow you the satisfaction of judging your solution to be superior to mine!). Only a knowledge of the basic notation and elementary ideas of set theory are assumed.

Abstraction lends enormous power to mathematics, as we learn early in life when we abstract the concept of number by observing the property that sets of two objects, for instance, have in common. Unfortunately, abstract ideas are assimilated very slowly, and so the level of abstraction is increased gently as the book progresses. The first chapter looks at vectors in two or three dimensions. These may well have been encountered previously in applied mathematics or physics, but are developed fully here in a way which lends 
itself to generalisation later. Geometrical ideas are stressed, as they underlie much of linear algebra.

Chapters 2 and 3 develop basic matrix algebra and apply it to the study of systems of linear equations. In Chapter 4, determinants are introduced, and here difficult choices have had to be made. I have chosen to give a treatment which is rather dated, but which is nevertheless rigorous enough for those demanding thoroughness. In doing so I have rejected the elegant modern approaches because of t.e level of sophistication. I have also rejected the compromise which introduces simplification by treating only the $3 \times 3$ case rigorously, because of its lack of thoroughness. It is true that the proofs included here are not central to modern linear algebra and that it is important only to acquire a certain facility with the manipulation of determinants. However, those who find the proofs difficult or not to their taste can acquire this facility simply by concentrating on the results and gaining experience with the examples and exercises. Those of a genuine mathematical curiosity who refuse to believe anything until it is demonstrated to their satisfaction will, I hope, gain some pleasure from the proofs.

Chapters 5 to 7 are concerned with the basic ideas of modern linear algebra: the notions of vector spaces and of structure-preserving maps between them. It is shown how the more abstract concepts here grow naturally out of the earlier material, and how the more powerful tools developed can be applied to obtain deeper results on matrices and on systems of linear equations. The final chapter gives another application, this time to the classification of conics and quadrics, and thereby emphasising once again the underlying geometry.

While great attention has been devoted to developing the material in this book slowly and carefully, it must be realised that nothing of any value in this world is achieved without some expenditure of effort. You should not expect to understand everything on first reading, and should not be discouraged if you find a particular proof or idea difficult at first. This is normal and does not in itself indicate lack of ability or of aptitude. Carry on as best you can and come back to it later, or, in the case of a proof, skip it altogether and concentrate on understanding the statement of the result. Rests are also important: ideas are often assimilated and inspiration acquired (in a manner not understood) during rest. But do at least some of the exercises; never assume that you have understood without putting it to the test.

This book is based on many years of teaching algebra to undergraduates, and on many hours of listening carefully to their problems. It has been influenced, inevitably, by the many excellent teachers and colleagues I have been fortunate to have, and I am happy to record my thanks to them. Any qualities which the book may have are due in very large part to them; the shortcomings are all my own. Finally I would like to thank Peter Oates at Macmillans whose idea this series was, and without whose encouragement (and patience when deadlines were missed!) this book would never have been written. 